\title{
A Big Push
}

\author{
Marvin L. Birnbaum, MD, PhD
}

Only engage, and then the mind grows beated;

Begin it, and the work will be completed.

Goethe, Faust, Prelude at the Theatre

Those of you who were able to participate in the 13th World Congress on Disaster and Emergency Medicine (WCDEM-13) in Melbourne in May 2003 were involved in a well-organized and well-conducted convocation in the midst of world chaos. Principal among the world problems at the time were the outbreak of the Severe Acute Respiratory Syndrome (SARS) and the early phases of the "pre-emptive" war in Iraq. We owe the members of the Organizing and Program Committees who conceived this excellent Congress our grateful thanks for their extraordinary vision used in assembling the Congress. Moreover, they allowed sufficient flexibility to include last-minute panel discussions on SARS and the Iraq conflict-which were delivered in a brilliant fashion.

Of great significance was the recognition of the importance of the relationships between disaster and emergency medicine and public health. It has become increasingly clear that the discipline of disaster medicine and emergency medicine deals with both population health and individual medical care. The development of both aspects of this new science must be fostered. Evolution of the public health aspects of this discipline are in line with the charges assigned to the WADEM by the World Health Organization (WHO) and other operational organizations. The WADEM is in an ideal circumstance to grapple with these issues as it is a non-operational, academic body that has no conflict of interest in dealing with the operational aspects of the science.

As I have discussed many times in this forum, over the last few years the World Association for Disaster and Emergency Medicine (WADEM) has been charged by the Asia-Pacific Conferences and the WHO to accomplish a long list of tasks that are essential for the development of the Science of Disaster and Emergency Medicine. In order to accomplish these tasks, the WADEM has formed a bevy of Standing Committees and Task Forces to meet these challenges. Importantly, to foster this process, the WCDEM-13 was organized along the structure of the WADEM's Committees and Task Forces. During the Congress, each of the Committees and Task Forces convened, the chairs and co-chairs were selected, and plans were evolved to enable each of them to create a comprehensive report in its specific area of responsibility to be presented at the 14th World Congress on Disaster and Emergency
Medicine (WCDEM-14) to be convened in Edinburgh, Scotland in May 2005. The presentations during the WCDEM-13 essentially jump-started the work of the Committees and Task Forces. The Congress piqued the interest of the participants in the work of the WADEM as many volunteered to work on the Committee or Task Force that interested them most. In addition, many new members to this organization jumped on board the WADEM train. Significant progress was made in several important areas. For example, the Education Committee embarked on the development of minimum standards and guidelines for the development of special competence in Disaster Medicine. Upon completion of its work, such standards will form the basis of curricula for special certifications and academic degrees in the discipline of Disaster Medicine. This Committee has convened multiple times since the Melbourne Congress.

In addition, the foundation was laid for the development of a Nursing Section to the WADEM. The proposal to establish a Section for International Disaster and Emergency Nursing will be prepared for the meeting of the WADEM Board of Directors during the WCDEM-14. The Task Force on Terrorism laid the groundwork for the two special-theme issues of this Journal dealing with Terrorism, of which this issue is the second in the series. And, the Task Force dealing with the Psychosocial aspects of disasters set the stage for the development of the position paper on levels of alert that precedes the Editor's Corner in this issue of PDM.

The accomplishments listed above only account for a limited part of the activities. Indeed, given the format of WCDEM-13, each of the Committees and Task Forces was kick-started during the Congress. It is up to the leadership of WADEM and each of the Task Forces and Committees to keep the ball rolling. These initiatives will form the basis of the 14th World Congress on Disaster and Emergency Medicine to be convened in Edinburgh in May 2005. We all eagerly await the reports of these bodies. What a great push forward-thank you, WCDEM-13, for your huge contributions to the science of Disaster and Emergency Medicine.

Begin: to have commenced is balf the deed.

Half yet remains:

Begin again on this and thou shall finish all.

Ausonius, Epigrams No. 15 from the Greek of Lucian 